\title{
The principled leadership scale: An integration of value-based leadership
}

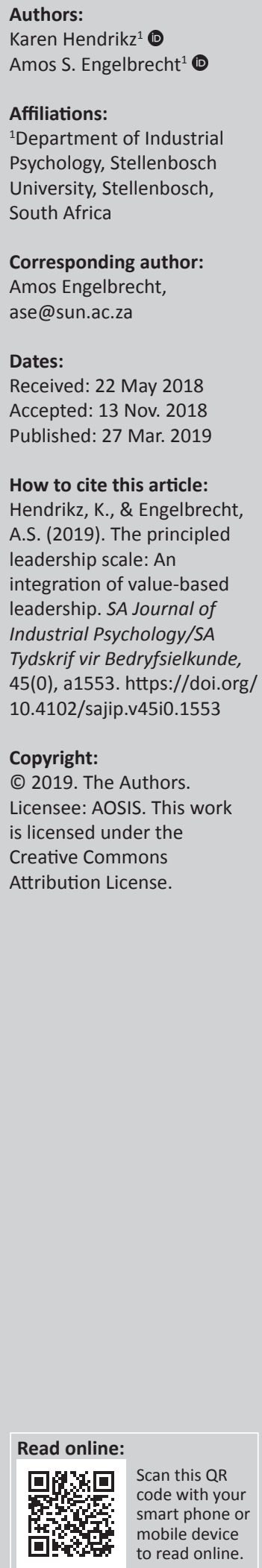

Orientation: A need exists to investigate leader behaviour necessary to curb the corruption that has infected and weakened South Africa's moral fibre. Such leader behaviour would need to be underpinned by a set of universal moral values.

Research purpose: The purpose of this study was to develop a new measure, the principled leadership scale (PLS), by integrating the value-based behaviours inherent in transformational, servant, authentic and ethical leadership.

Motivation for the study: Leader behaviour intrinsic to value-based leadership was found to be closely aligned with universal moral values. Because the study found a considerable overlap between the behaviours mentioned in the value-based leadership theories, it sought to integrate these behaviours under one construct and to develop a reliable and valid scale to assess this construct.

Research approach/design and method: Data from the quantitative study were analysed by means of item analysis, exploratory and confirmatory bi-factor analysis conducted via structural equation modelling.

Main findings: The confirmatory bi-factor solution corroborated a strong general principled leadership factor and four moderately weak group factors. The statistical analyses provided good fit of the PLS measurement model with the empirical data.

Practical and managerial implications: The study found acceptable measurement properties of the PLS that may be used for applications, such as the selecting, training and developing of ethical leadership in organisations.

Contribution/value-add: The study adds value in that it is the first to integrate the four valuebased leadership theories under one construct and to develop a potential psychometrically sound instrument to measure principled leadership.

Keywords: Ethical leadership; value-based leadership; principled leadership; authentic leadership; servant leadership; transformational leadership; confirmatory bi-factor analysis.

\section{Introduction}

The Enron debacle of 2001 could possibly be regarded as one of the most complex examples of unethical and corrupt business practices of the past two decades. Despite the lessons that leaders could have learnt from this debacle, history keeps repeating itself as daily reports of unethical behaviour, greed and the abuse of power by public and private organisational leaders continue to make headline news. Recent international examples include the Federation of International Football Association (FIFA), Volkswagen, Panama Papers and Steinhoff scandals, while issues such as state capture and gross misuse of government funds continue to dominate South African news.

The devastating result of having an organisation managed by corrupt leaders is that the corruption does not remain closeted behind the boardroom door. The leaders' corrupt behaviour tends to infiltrate and pollute the entire organisation. This phenomenon has its roots in the social learning theory (SLT), developed by Bandura (Bandura, cited in Mayer, Kuenzi, Greenbaum, Bardes, \& Savador, 2009), which suggests that individuals will strive to emulate the behaviour of role models in their work environment. Employees witness reward and punishment for the behaviour that is deemed acceptable or unacceptable in their workplace and will adjust their behaviour in accordance with what is deemed an acceptable behaviour (Mayer et al., 2009, p. 2). In organisations where leaders are corrupt, display immoral behaviour as the norm and are seen to reap positive rewards despite this behaviour, employees will learn to emulate such behaviour to similarly reap rewards for themselves. 
Several methods for curbing the corrupt behaviour of leaders and their followers have been proposed in the literature. These include adherence to and penalties for breaking the law, organisational policies, professional codes of conduct that prescribe appropriate work behaviour, codes of ethics, ethics training and ethics committees (Mayer et al., 2009; Sauser, 2005). That these methods are able to enforce ethical conduct of leaders in organisations is, however, doubtful. The organisations linked to the scandals referred to above are all guided by such laws and codes, and yet corruption has triumphed.

Pillay (2014) and Sauser (2005) suggest an alternate solution to this problem. Sauser $(2005$, p. 346) proposes that the conscience, based on the individual's value system, is what ultimately holds people accountable for their actions. This value system becomes the leader's inner moral compass and guides the leader's actions from the inside out (Pillay, 2014). What is therefore needed is for organisations to appoint leaders who have a strong moral compass and who, based on this, rather than on moral regulations imposed from the outside, become role models of desirable moral behaviour, which will cascade down the ranks of an organisation via social learning (Mayer et al., 2009).

In addition to role modelling, leadership development training appears to have some value in instilling appropriate moral behaviour in leaders. However, traditional forms of leadership training, whereby leaders attend short conferences or training sessions, appear to add little more value than a cognitive, short-lived, motivational experience for developing leaders (Allio, 2005). For leaders to learn to lead effectively, their behaviour must change in line with effective leadership outcomes. Effective leadership encompasses establishing the vision, values and purpose of an organisation and building a culture that embraces these in such a way that growth and survival of the organisation are achieved (IoDSA, 2016). The change in behaviour necessary to achieve effective leadership does not occur through a once-off training session. It requires mentoring and coaching by appropriate role models, over a period of time, until the required behaviour is learnt and entrenched (Allio, 2005).

Some important questions to consider before embarking on a programme to develop effective leaders and strengthen their moral compass, are the following: whose concept of morality is one referring to?; can universal standards of morality be defined?; and are such universal standards of morality necessary?

The necessity of a universal understanding of morality is aptly summarised by Bell (cited in Kinnear, Kernes, \& Dautheribes, 2000) as follows:

Without universal moral standards we are left with no way to condemn cannibalism, physical torture, mutilation, wife beating, child abuse, slavery, murder and genocide if they are part of the habitual practice and cultural traditions of a group. (p. 6)
This statement highlights the need to move away from moral relativism towards universally recognised moral principles, if behaviour is to be judged as either ethical or unethical.

Kinnear et al. (2000) and Schwartz (2005) conducted studies in which they attempted to establish such universal principles. Their studies included analysis of the sacred texts of the major religions of the world, codes of secular organisations that focus on morality (e.g. the American Humanist Association, the United Nations, the Caux Roundtable Principles), corporate codes of ethics and business ethics literature. Their findings revealed the following as universal moral values (Kinnear et al., 2000, pp. 9-10; Schwartz, 2005, p. 39):

1. commitment to something greater than oneself (a supreme being, transcendent purpose or meaning to one's existence, truth or justice)

2. trustworthiness (including honesty, integrity, transparency, reliability, humility and loyalty)

3. respect for self, human race, the environment and other living beings

4. responsibility (including accountability, excellence and self-discipline)

5. fairness (including process, impartiality and equity)

6. caring (including avoiding unnecessary harm, compassion, forgiveness and tolerance)

7. citizenship (including notions of obeying laws and protecting the environment).

The preceding list provides a guideline to what universally accepted moral behaviour looks like. Organisations that aim to cultivate a culture in which ethical behaviour is the norm should therefore seek to employ leaders who display this behaviour, so that it can be learnt by followers and may cascade down the levels of the organisation.

A starting point in identifying such leaders would be to assess leaders by means of the scales of leadership theories, which are underpinned by the moral principles described above. The most significant leadership theories that speak to these moral behaviours are transformational, servant, authentic and ethical leadership, referred to in this study as value-based leadership theories. This leads to the aim of the study.

\section{Aim of the study}

The purpose of this study was to distil an integrated leadership concept, under the construct principled leadership, from the salient and overlapping features of the four valuebased leadership theories and to develop a reliable and valid scale to measure this construct.

\section{Transformational leadership}

Transformational leadership focuses largely on the principle of being committed to something greater than oneself. The transformational leader typically inspires followers to move beyond focusing on their own interests to focusing on a 
higher purpose, such as an organisational goal (Bass, cited in Hemsworth, Muterera, \& Baregheh, 2013).

The theory has received criticism with regard to the motivation behind such inspiration by transformational leaders, as it may serve the organisation more than the follower, rendering the ethical behaviour of such a leader questionable (Stephens, D'Intino \& Victor, cited in Yukl, 1999). The strong moral component of the transformational leader is defended by several researchers, however, who argue that transformational leaders inspire followers towards ethical behaviour, and doing what is right in pursuit of higher goals (Engelbrecht, Van Aswegen, \& Theron, 2005).

This is confirmed in the details of at least three of the subscales of the Multifactor Leadership Questionnaire (MLQ), the most widely used instrument to measure transformational leadership (Hemsworth et al., 2013). The MLQ's subscale Idealised Influence Behaviours focuses on communicating important values and beliefs, the necessity of having a strong sense of purpose or meaning (Kinnear et al., 2000; Schwartz, 2005) and the need to consider the moral and ethical consequences of decisions (Hemsworth et al., 2013). Humility (Kinnear et al., 2000; Schwartz, 2005) in the leader's thinking is addressed in the subscale Intellectual Stimulation, where the need to seek the opinions of others is emphasised. The subscale Individualised Consideration explores the leader's ability to coach and mentor followers and to care (Kinnear et al., 2000; Schwartz, 2005) about developing their individual strengths (Hemsworth et al., 2013, p. 857). The fourth subscale, Inspirational Motivation (Hemsworth et al., 2013, p. 857), which measures the leader's ability to articulate a compelling vision and inspire followers with a view to the future, evaluates important leader behaviours. However, these behaviours can only be considered as value-based when the vision that is communicated is morally sound.

\section{Servant leadership}

The focus of servant leadership is the leader's desire to serve others with the aim of seeing them grow into 'healthier, wiser, freer, more autonomous beings' (Greenleaf, cited in Barbuto \& Wheeler, 2006, p. 301). The motivation behind this desire to serve lies in the leader's obedient gratitude towards a higher power (Sendjaya, Sarros, \& Santora, 2008). While transformational leadership places an emphasis on the follower's achievement of transcendent, rather than selfdirected goals, servant leadership regards the achievement of transcendent goals (e.g. strategic organisational goals) as a natural, long-term outflow of the short-term focus of assisting (serving) the follower in his or her self-development (Stone, cited in Sendjaya et al., 2008).

Servant leadership thus has strong links to the universal principles of being committed to something greater than oneself and caring for others (Kinnear et al., 2000; Schwartz, 2005). These principles are embedded in dimensions of servant leadership such as Altruistic Calling and Emotional Healing (Barbuto \& Wheeler, 2006); Voluntary Subordination
(Sendjaya et al., 2008) and Empowerment, Standing Back, and Forgiveness (Van Dierendonck \& Nuitjen, 2011).

Notions of respect, responsibility, fairness, trustworthiness and citizenship (Kinnear et al., 2000; Schwartz, 2005) are also embedded in servant leadership. Beyond developing the follower, servant leaders must ensure that they act responsibly by ensuring that the ends sought in business are morally legitimate and justified (Sendjaya et al., 2008). Furthermore, servant leaders are stewards of the organisation in that they provide direction, ensure that the organisation contributes positively to society and that followers are held accountable for the performance they can control (Van Dierendonck \& Nuitjen, 2011). Sendjaya et al. (2008) touch on the principle of fairness, which requires the servant leader to treat followers fairly, and with radical equality. Finally, the notion of trustworthiness is embedded in the servant leadership dimensions Authentic Self (Sendjaya et al., 2008) and Authenticity and Humility (Van Dierendonck \& Nuitjen, 2011). These dimensions focus on the servant leader's ability to make themselves vulnerable and accountable to others and to be true, both publicly and privately, to their stated intentions and commitments (Coetzer, Bussin, \& Geldenhuys, 2017; Sendjaya et al., 2008; Van Dierendonck \& Nuitjen, 2011).

\section{Authentic leadership}

Authentic leadership is largely focused on the principle of trustworthiness, particularly the value of integrity (Cianci, Hannah, Roberts, \& Tsakumis, 2014; Kinnear et al., 2000; Schwartz, 2005). Essentially, authentic leaders are true to their beliefs and values and base their actions on these, do not conform to the expectations of others or copy what others do (Walumbwa, Avolio, Gardner, Wernsing, \& Petersen, 2008). Furthermore, authentic leaders demonstrate self-control that is guided by internalised moral standards and values rather than group pressures (Walumbwa et al., 2008). The relational transparency and ability of the authentic leader to 'walk his or her talk' has been proven to promote trust in the leader (Hassan \& Ahmed, 2011).

Despite this, Shamir and Eilam (cited in Walumbwa et al., 2008) warn that authenticity can be a dangerous attribute in narcissistic or other dysfunctional personalities. Walumbwa et al. (2008), however, argue that true authentic leadership requires a high degree of self-awareness and self-acceptance, which is preceded by high moral development. Dysfunctional personalities do not achieve the necessary moral development to be sufficiently self-aware or self-accepting to have transparent, authentic relationships with others.

Further principles that are embodied in authentic leadership are self-restraint, humility and tolerance (Kinnear et al., 2000; Schwartz, 2005). While authentic leaders are transparent about their true feelings, they exercise the self-restraint necessary to minimise displays of inappropriate emotions (Walumbwa et al., 2008). Humility and tolerance are displayed in an authentic leader's ability to ask others for 
opinions and to be open to others challenging their point of view (Neider \& Schriesheim, 2011).

\section{Ethical leadership}

It appears from the literature that some confusion still exists around the precise definition of ethical leadership (Yukl, Mahsud, Hassan, \& Prussia, 2013). A definition commonly used to define ethical leadership is the one provided by Brown, Trevino and Harrison (2005): it is 'the demonstration of normatively appropriate conduct through personal actions and interpersonal relationships, and the promotion of such conduct to followers through two-way communication, reinforcement and decision-making' (Brown et al., 2005, p. 120). Kalshoven, Den Hartog and De Hoogh (2011) developed a multidimensional measure of ethical leadership, based on the work of Brown et al. (2005). Kalshoven et al. (2011) operationalised ethical leadership in terms of seven dimensions, namely fairness, people orientation, role clarification, ethical guidance, concern for sustainability, power sharing and integrity.

The definition of Brown et al. (2005) is problematic in the sense that it does not define what normatively appropriate behaviour is (Giessner \& Van Quaquebeke, 2010) and places ethical leadership into the realm of ethical relativity, which, as discussed in the introduction, is not ideal. To regard behaviour as ethical or not, requires a definition of how ethical behaviour is recognised.

Eisenbeiss (2012) attempted doing this by analysing Western, Eastern and to some extent, African viewpoints that relate to four ethical orientations: (1) the humane, (2) justice, (3) responsibility and sustainability and (4) moderation orientations. The ethical behaviours underpinning these ethical considerations, respectively, are: (1) treating others with respect and not as a means to an end; (2) interacting with followers in a way that is fair, consistent and nondiscriminatory; (3) taking responsibility for, and being concerned about, the well-being of society and the environment and (4) showing self-restraint regarding emotions, displaying humility, being careful and wise in finding a balance between stakeholder interests and organisational objectives (Eisenbeiss, 2012, p. 792).

In a similar attempt to establish the behaviours underlying ethical leadership, Yukl et al. (2013) analysed various scales measuring ethical leadership, as well as authentic and servant leadership. The behaviours they found to be most unique and pertinent to ethical leadership included: honesty and integrity, behaviour that purposefully communicates ethical standards to followers, fairness, kindness, compassion and concern for others (Yukl et al., 2013, pp. 40-41). Engelbrecht, Heine and Mahembe (2017) also found a positive relationship between integrity and ethical leadership, as well as trust in the leader (trustworthiness).

The above behaviours speak to Kinnear et al. (2000) and Schwartz's (2005) universal principles of having respect for others and the environment, responsibility (including selfrestraint), trustworthiness, fairness, humility and caring. Taking this into consideration, Brown et al.'s (2005) definition of ethical leadership could be expanded as follows:

... the demonstration of fairness, respect, responsibility, trustworthiness, humility and caring through personal actions and interpersonal relationships, and the promotion of such behaviours in followers through two-way communication, reinforcement and decision-making. (p. 120)

\section{Summary of value-based leadership theories}

In summary, each theory focuses on a unique aspect of value-based leadership. If an organisation wanted to assess a leader holistically on all the principles underlying these theories, they would have to use a battery of assessments from the various leadership theories to do so. This could become an expensive and time-consuming exercise. A more parsimonious approach would be to have one assessment that covers all aspects of value-based leadership.

Furthermore, while each theory makes a unique contribution, there is a considerable overlap of behaviours mentioned in the theories. For example, having a strong sense of purpose, being humble and basing actions on moral values is inherent in all four value-based theories. Caring for and developing followers underpins transformational, servant and ethical leadership. Being vulnerable, transparent and self-aware is integral to authentic, servant and ethical leaders. The researchers thus question the usefulness of focusing on individual theories when, essentially, they all emphasise the importance and effectiveness of moral leadership.

Based on the integration of the current theories of valuebased leadership, the construct of principled leadership was isolated and is defined as follows: principled leaders inspire and motivate others with a sense of purpose that goes beyond their own needs and desires; they are trustworthy and act as role models of universally accepted moral behaviour by mastering their behaviour and interactions with others through humility, openness and vulnerability; by focusing on the empowerment of others and by being accountable for their own actions while holding others to account for theirs.

\section{Research method Research design and plan}

A quantitative, ex post facto design was used in this study. Paper-based and web-based, electronic questionnaires were used to gather the data. The research plan was based on the generic steps for scale development presented by McKenzie, Podsakoff and Podsakoff (2011), and took place as discussed below.

\section{Specification of the principled leadership scale}

The dimensions and items of the principled leadership scale (PLS) were specified in three steps. Firstly, the researchers compiled a list of behaviours inherent to the four value-based 
leadership theories to determine the extent to which the behaviours overlap or are unique to the various theories.

Next, the researchers allocated the behaviours into categories of behaviour that appeared to have common ground. The overlapping behaviours and the dimensions of various scales of value-based leadership styles (Barbuto \& Wheeler, 2006; Brown et al., 2005; Hemsworth et al., 2013; Neider \& Schriesheim, 2011; Sendjaya et al., 2008; Spangenberg \& Theron, 2005; Van Dierendonck \& Nuitjen, 2011; Walumbwa et al., 2008; Yukl et al., 2013) were used as a guideline to do this. The following categories of behaviour formed the basis of the dimensions defined for the PLS:

- role modelling of universal moral values and trustworthiness

- moral visioning

- authenticity and self-mastery of the leader

- developing and empowering others

- taking accountability for organisational outcomes and longevity of the organisation

- being situationally aware and open to change.

Initially, six dimensions were identified, namely Internalised Values, Self-awareness, Principled Strategist, Other-centred, Stewardship and Change Agent. Eighty-one items to measure these dimensions were generated deductively through detailed examination of the literature. Of these, 17 items were derived directly from specific scales: Servant Leadership Survey (SLS) (Van Dierendonck \& Nuitjen, 2011) (six items), Authentic Leadership Questionnaire (ALQ) (Walumbwa et al., 2008) (four items), Authentic Leadership Inventory (ALI) (Neider \& Schriesheim, 2011) (four items), Ethical Leadership Scale (ELS) (Brown et al., 2005) (one item) and Ethical Leadership Questionnaire (ELQ) (Yukl et al., 2013) (two items).

Finally, face and content validity of the scale were established via the Delphi technique (Hsu \& Sandford, 2007). The scale was emailed to South African academics and professionals practising in the field of leadership.

Several changes were made after reviewing the feedback provided by 13 participants. The wording of several items was changed. Some items were moved to other dimensions. The number of items was reduced from 81 to 58 . The number of dimensions was also reduced from six to four (see Table 1).

The dimensions Change Agent and Principled Strategist were deleted. Upon review, it became clear that managing change, while important to leadership, is not necessarily a value-based behaviour. Most items contained in principled strategist were found to also assess internalised values or stewardship, rendering this dimension redundant. Items, which originally fell under principled strategist, were allocated to the remaining four dimensions.

The dimension Internalised Values was renamed Trustworthiness, Self-Awareness became Self-Mastery, Other-centred became Empowerment and Stewardship became Accountability. The final dimensions with their definitions and sample items are provided in Table 1. A five-point Likert scale ( $1=$ strongly disagree; 5 = strongly agree) was used to measure the items.

\section{Sample selection and data collection}

Purposive, non-probability sampling was used to select participants from various companies in the Western Cape, Gauteng and Kwa-Zulu Natal. The participating organisations included software development and consulting services, retail, wine making, construction and public service. A total of 308 questionnaires were returned. The racial split of the sample was as follows: white $(84 \%)$, mixed race $(10 \%)$, Indian (2\%) and African (4\%). Of the respondents, 58\% were working in non-managerial positions, $31 \%$ in lower to mid-level management and $11 \%$ in senior to top management-level positions. The average age of the participants was 33 years.

Electronic and/or paper-based questionnaires were sent either to a contact person at the organisation for further distribution or directly to the participants.

\section{Statistical analysis}

Statistical Package for the Social Sciences (SPSS 23.0) was used to assess the internal consistency of the PLS by means

TABLE 1: Dimensions of the principled leadership scale and item samples.

\begin{tabular}{|c|c|}
\hline Dimension & Sample items \\
\hline $\begin{array}{l}\text { Trustworthiness: The leader's actions are based on a strong foundation of universally accepted moral } \\
\text { principles (values). These principles include being committed to something greater than oneself and having } \\
\text { a deep-seated sense of calling, humility, integrity, honesty, transparency, self-discipline and reliability. Such } \\
\text { leaders are role models who act in agreement with these values and who promote a vision and strategy for } \\
\text { the organisation that is inspiring, meaningful and morally sound. }\end{array}$ & $\begin{array}{l}\text { - My manager's actions are consistent with commonly accepted } \\
\text { moral principles (i.e. he or she is not greedy or selfish, is honest, } \\
\text { has integrity and is trustworthy, transparent and reliable). } \\
\text { - My manager has zero tolerance for dishonest business practices. }\end{array}$ \\
\hline $\begin{array}{l}\text { Self-mastery: The leader continually develops self-awareness by seeking feedback from others and } \\
\text { choosing to react positively to the feedback. The leader's thinking is marked by openness, courage, } \\
\text { empathy and autonomy. Self-awareness leads to a good understanding of the leader's strengths and } \\
\text { weaknesses, and of the impact that these have on others. The leader uses this understanding to exercise } \\
\text { appropriate self-monitoring over his or her behaviour and to interact effectively with others. }\end{array}$ & $\begin{array}{l}\text { - My manager thinks before he or she acts. } \\
\text { - My manager encourages me to challenge his or her ideas. }\end{array}$ \\
\hline $\begin{array}{l}\text { Empowerment: Rather than being focused on their own agenda, leaders place a priority on mentoring and } \\
\text { developing others and see this as one of their primary responsibilities. They build confidence and } \\
\text { self-efficacy in team members by empowering them and by creating an environment that is fair and } \\
\text { respectful. Leaders recognise that team members have unique development needs, strengths and } \\
\text { weaknesses. They care for team members and give them individual support. }\end{array}$ & $\begin{array}{l}\text { - My manager regularly provides me with constructive feedback. } \\
\text { My manager provides opportunities for me to learn new skills, } \\
\text { when possible. }\end{array}$ \\
\hline $\begin{array}{l}\text { Accountability: Leaders regard themselves as stewards of the organisation who are responsible for the } \\
\text { long-term success of the organisation. Success should be understood as organisational well-being in the } \\
\text { bigger picture, which includes financial and operational success, ethical interaction with all stakeholders } \\
\text { and the environment, as well as employee well-being. Accountability includes taking responsibility for } \\
\text { organisational performance and holding others accountable for their performance. Ultimately, } \\
\text { accountability aims to ensure the longevity of the organisation and to leave a positive legacy. }\end{array}$ & $\begin{array}{l}\text { - My manager takes responsibility when things in our team or the } \\
\text { organisation go wrong. } \\
\text { - My manager holds me accountable for achieving agreed goals. }\end{array}$ \\
\hline
\end{tabular}


of the Cronbach's alpha coefficients $(\alpha)$. Exploratory factor analysis (EFA) was performed to establish unidimensionality of the subscales of the PLS. In particular, the principal-axis factoring extraction method with the direct oblimin-rotated solution was used in SPSS 23.0. The cut-off point for substantial factor loadings was loadings $\geq 0.40$ (Hinkin, 1998).

Confirmatory factor analysis (CFA) was performed on the measurement model of PLS in LISREL 8.80 (Jöreskog \& Sörbom, 2006) to determine whether the theorised model was supported by the data collected.

\section{Ethical considerations}

To mitigate any potential ethical risks relating to the research, ethical clearance for the research was sought from the Research Ethics Committee of Stellenbosch University. Furthermore, informed consent was sought from participating employers and respondents, the purpose of the research was clearly explained to all the participants, confidentiality and anonymity were guaranteed and feedback was provided in aggregate format only.

\section{Results}

The results of the measurement model, as theoretically derived from the literature study, are reported below.

\section{Missing values}

The questionnaires were completed by 308 participants. Of these, eight data sets had missing values and thus these were deleted, leaving 300 complete data sets to work with.

\section{Initial statistical analysis of the principled leadership scale}

Item, exploratory factor analysis and CFA were conducted on the initial version of the PLS, which contained four dimensions and 58 items.

\section{Reliability analysis}

The item analysis was conducted using the SPSS's reliability analysis, which revealed good $(>0.80)$ Cronbach's alpha values ranging from 0.89 to 0.96 , which exceeded the minimum acceptable cut-off value of 0.70 (Nunnally, 1978). In addition, the corrected item-total correlations (0.44-0.84) were above the desired correlation value of 0.30 for all subscales (Pallant, 2013).

\section{Exploratory factor analysis}

Exploratory factor analysis was conducted to confirm the unidimensionality of each subscale. Adequate KaiserMeyer-Olkin (KMO) scores (0.90-0.96) were achieved $(>0.60)$ (Pallant, 2013), which rendered all the subscales factor analysable. Principal-axis factoring was used as the extraction method and the oblimin procedure was used to rotate the factor matrix. The number of factors was determined by the 'eigenvalue greater than 1 ' rule and scree plot.
All subscales except Accountability met the criteria for unidimensionality. The rotated factor matrix for accountability produced two factors. After enforcing one-factor and deleting the item with the lowest loading (PCL29), the criterion for unidimensionality for accountability was met. In all subscales, the factor loadings of the unrotated factor matrix were substantial (>0.40) (Hinkin, 1998) (see Table 2).

\section{Evaluating the measurement model of the principled leadership scale}

The initial CFA of the measurement model (correlated fourfactor model and 57 items) revealed a root-mean-square error of approximation (RMSEA) of 0.0560 and a $p$-value of close fit of 0.000595. Thus, the initial CFA achieved an acceptable RMSEA value but not close fit for the measurement model. As close fit is a requirement for a behavioural measure such as the PLS, the measurement model was further examined. An inspection of the PHI matrix of the correlated model revealed that the correlations between the dimensions of the PLS were very high (0.867-0.979), which raised serious concerns about the discriminant validity with which the PLS measured the four dimensions of principled leadership.

\section{Bi-factor model for the principled leadership scale}

Inspection of the modifications associated with the PLS correlated four-factor measurement model (58 items) indicated numerous statistically significant $(p<0.01)$ modification index values, associated with the off-diagonal covariance terms in the theta-delta measurement error variance-covariance matrix. The large number of statistically significant $(p<0.01)$ modification index values associated with the off-diagonal elements of theta-delta (currently fixed to zero) suggested an additional source of systematic variance underpinning all the items but that is currently not acknowledged by the model. This suggests that a bi-factor model (Chen, West, \& Sousa, 2006; Reise, 2012) in which each item measures one of four narrow, specific principled leadership dimensions (group factors) but in which all 58 items also reflect a broad, more general, principled leadership factor might possibly display better fit. In terms of bi-factor models, the relationship between the general factor and group factors is assumed to be orthogonal or unrelated, because the contribution made by the group factors to the item variances is over and above the contribution made by the general factor (Chen et al., 2006).

The goodness-of-fit statistics for the bi-factor model for principled leadership is presented in Table 3. The results of the fit indices showed that the bi-factor model met the criterion for close fit $(p>0.05)$, supporting the close fit hypothesis. The goodness-of-fit index (GFI) produced a poor

TABLE 2: Exploratory factor analysis output for the revised principled leadership scale dimensions.

\begin{tabular}{lccc}
\hline Dimension & Number of items & Factor loadings & \% Variance explained \\
\hline Trustworthiness & 16 & $0.61-0.87$ & 58.78 \\
Self-mastery & 17 & $0.62-0.83$ & 59.57 \\
Empowerment & 13 & $0.45-0.85$ & 56.03 \\
Accountability & 11 & $0.56-0.76$ & 47.59 \\
\hline
\end{tabular}


TABLE 3: Goodness-of-fit indices for the principled leadership scale (58 items) measurement models.

\begin{tabular}{lcccccccccc}
\hline Model & S-B $\chi^{2}$ & Normal theory $\chi^{2}$ & $d f$ & Scaled $\Delta$ S-B $\chi^{2}$ & RMSEA & Pclose fit & SRMR & GFI & NFI & CFI \\
\hline 1-Factor & 3747.51* & $4829.71^{*}$ & 1595 & $828.84 * 4 B F-1 F$ & 0.067 & 0.00 & 0.049 & 0.642 & 0.970 & 0.983 \\
4-Factor & 3105.66* & $3977.91^{*}$ & 1589 & $251.46 * 4 F-1 F$ & 0.057 & 0.00 & 0.049 & 0.686 & 0.975 & 0.988 \\
4-Bi-factor & 2576.33* & $3254.43^{*}$ & 1531 & $414.18^{*} 4 \mathrm{BF}-4 \mathrm{~F}$ & 0.048 & 0.87 & 0.040 & 0.727 & 0.979 & 0.992 \\
\hline
\end{tabular}

$\mathrm{S}-\mathrm{B} \chi^{2}$, Sattora-Bentler scaled chi-square; Normal theory $\chi^{2}$, normal theory chi-square; $d f$, degrees of freedom; scaled $\Delta \mathrm{S}$-B $\chi^{2}$, scaled difference in S-B chi-square; RMSEA, root-mean-square error of approximation; Pclose fit, $p$-value for test of close fit (RMSEA < 0.05); SRMR, standardised root mean residual; GFI, goodness-of-fit index; NFI, normed fit index; CFI, comparative fit index; 1-Factor, one-factor PLS measurement model; 4-Factor, four-factor PLS measurement model; 4-Bi-factor, four Bi-factor PLS measurement model; PLS, principled leadership scale.

$*, p<0.01$.

TABLE 4: Completely standardised LAMBDA-X factor loadings of the bi-factor measurement model.

\begin{tabular}{|c|c|c|c|c|c|c|}
\hline Item & Trust & Selfm & Empower & Account & Gen & $\begin{array}{c}\text { Variance } \\
\text { explained }\left(R^{2}\right)\end{array}$ \\
\hline Q9 & $0.094^{*}$ & - & - & - & $0.782 *$ & 0.620 \\
\hline Q10 & - & $0.217^{*}$ & - & - & $0.681 *$ & 0.511 \\
\hline Q11 & 0.078 & - & - & - & $0.789 *$ & 0.629 \\
\hline Q12 & - & - & $0.146^{*}$ & - & $0.655^{*}$ & 0.450 \\
\hline Q13 & - & - & - & -0.032 & $0.738^{*}$ & 0.546 \\
\hline Q14 & - & $-0.218^{*}$ & - & - & $0.695^{*}$ & 0.531 \\
\hline Q15 & 0.198* & - & - & - & $0.782 *$ & 0.651 \\
\hline Q16 & - & $-0.283^{*}$ & - & - & $0.753^{*}$ & 0.647 \\
\hline Q17 & - & - & - & 0.065 & $0.755^{*}$ & 0.575 \\
\hline Q18 & - & - & $0.362^{*}$ & - & $0.663^{*}$ & 0.571 \\
\hline Q19 & - & - & - & $0.292^{*}$ & $0.575^{*}$ & 0.415 \\
\hline Q20 & - & $-0.243^{*}$ & - & - & $0.698^{*}$ & 0.546 \\
\hline Q21 & $0.314^{*}$ & - & - & - & $0.703^{*}$ & 0.593 \\
\hline Q22 & - & 0.085 & - & - & $0.674^{*}$ & 0.462 \\
\hline Q23 & $0.247^{*}$ & - & - & - & $0.763 *$ & 0.643 \\
\hline Q24 & - & - & $0.153^{*}$ & - & $0.760^{*}$ & 0.601 \\
\hline Q25 & - & - & - & $0.196^{*}$ & $0.567^{*}$ & 0.360 \\
\hline Q26 & - & $-0.133^{*}$ & - & - & $0.729 *$ & 0.549 \\
\hline Q27 & 0.060 & - & - & - & $0.821^{*}$ & 0.678 \\
\hline Q28 & - & $-0.298^{*}$ & - & - & $0.753^{*}$ & 0.656 \\
\hline Q29 & - & - & - & $0.306^{*}$ & $0.611^{*}$ & 0.467 \\
\hline Q30 & - & - & $0.232^{*}$ & - & $0.723^{*}$ & 0.576 \\
\hline Q31 & - & - & - & $0.626^{*}$ & $0.465 *$ & 0.608 \\
\hline Q32 & - & - & $0.237^{*}$ & - & $0.714^{*}$ & 0.566 \\
\hline Q33 & - & $0.115^{*}$ & - & - & $0.786^{*}$ & 0.630 \\
\hline Q34 & - & $-0.299 *$ & - & - & $0.697^{*}$ & 0.575 \\
\hline Q35 & - & - & - & $0.238^{*}$ & $0.610^{*}$ & 0.428 \\
\hline Q36 & $-0.149 *$ & - & - & - & $0.713^{*}$ & 0.531 \\
\hline Q37 & - & - & - & $0.486^{*}$ & $0.433^{*}$ & 0.423 \\
\hline Q38 & - & $-0.362^{*}$ & - & - & $0.765^{*}$ & 0.717 \\
\hline Q39 & 0.008 & - & - & - & $0.761^{*}$ & 0.579 \\
\hline Q40 & - & $-0.271^{*}$ & - & - & $0.736^{*}$ & 0.616 \\
\hline Q41 & - & - & $0.378^{*}$ & - & $0.759 *$ & 0.719 \\
\hline $\mathrm{Q} 42$ & - & - & $0.257^{*}$ & - & $0.703^{*}$ & 0.560 \\
\hline Q43 & - & - & - & $0.315^{*}$ & $0.677^{*}$ & 0.557 \\
\hline Q44 & - & 0.078 & - & - & $0.761^{*}$ & 0.586 \\
\hline Q45 & - & $-0.331^{*}$ & - & - & $0.746^{*}$ & 0.667 \\
\hline Q46 & - & $-0.353^{*}$ & - & - & $0.739 *$ & 0.671 \\
\hline Q47 & - & - & 0.112 & - & $0.469 *$ & 0.233 \\
\hline Q48 & - & - & - & $0.287^{*}$ & $0.612 *$ & 0.457 \\
\hline Q49 & -0.074 & - & - & - & $0.703^{*}$ & 0.500 \\
\hline Q50 & - & $-0.136^{*}$ & - & - & $0.710^{*}$ & 0.523 \\
\hline Q51 & - & - & $0.376^{*}$ & - & $0.772^{*}$ & 0.737 \\
\hline Q52 & - & - & - & $0.206^{*}$ & $0.587^{*}$ & 0.388 \\
\hline Q53 & $0.141^{*}$ & - & - & - & $0.789 *$ & 0.642 \\
\hline Q54 & - & $-0.188^{*}$ & - & - & $0.779 *$ & 0.642 \\
\hline Q55 & - & - & $0.102^{*}$ & - & $0.714^{*}$ & 0.520 \\
\hline Q56 & $0.115^{*}$ & - & - & - & $0.766^{*}$ & 0.600 \\
\hline Q57 & -0.020 & - & - & - & $0.701^{*}$ & 0.491 \\
\hline Q58 & - & $-0.158^{*}$ & - & - & $0.736^{*}$ & 0.566 \\
\hline
\end{tabular}

Table 4 continues on the next page $\rightarrow$
TABLE 4 (Continues...): Completely standardised LAMBDA-X factor loadings of the bi-factor measurement model.

\begin{tabular}{lcccccc}
\hline Item & Trust & Selfm & Empower & Account & Gen & $\begin{array}{c}\text { Variance } \\
\text { explained }\left(\boldsymbol{R}^{2}\right)\end{array}$ \\
\hline Q59 & - & - & $0.454^{*}$ & - & $0.620^{*}$ & 0.591 \\
Q60 & -0.066 & - & - & - & $0.753^{*}$ & 0.572 \\
Q61 & $0.370^{*}$ & - & - & - & $0.675^{*}$ & 0.592 \\
Q62 & - & - & 0.050 & - & $0.742^{*}$ & 0.553 \\
Q63 & - & - & - & 0.034 & $0.601^{*}$ & 0.363 \\
Q64 & 0.054 & - & - & - & $0.609^{*}$ & 0.374 \\
Q65 & - & - & 0.032 & - & $0.637^{*}$ & 0.407 \\
Q66 & $0.421^{*}$ & - & - & - & $0.635^{*}$ & 0.580 \\
\hline
\end{tabular}

Trust, Trustworthiness; Selfm, Self-Mastery; Empower, Empowerment; Account, Accountability; Gen, general factor; $R^{2}$, proportion variance explained. $*, p<0.05$.

model fit $(<0.90)$, but the RMSEA, standardised root mean residual (SRMR) and relative fit indices indicated good model fit (Hooper, Coughlan, \& Mullen, 2008). Overall, the bi-factor measurement model showed good fit.

All 58 items loaded statistically significantly $(z$ values $\geq|1.64|, p<0.05^{1}$ ) on the general factor (see Table 4 ). Of these items, 55 achieved high (>0.50) standardised loadings on the general factor. The general factor and a group factor explained more than $50 \%$ of the variance in 45 of the items. Therefore, $78 \%$ of the items may be regarded as highly valid items describing the general and group factors as designated. The general factor tended to explain more variance in the items than the group factors. The majority of the items loaded unsatisfactory low $(<0.30)$ on the group factors they were earmarked to reflect.

An examination of the PHI matrix of the bi-factor model revealed that low to moderate (varied between 0.032 and 0.566 ) correlations were found between the dimensions of the PLS (see Table 5).

\section{Comparison of different measurement models}

To evaluate the suitability of the bi-factor measurement model, chi-square difference tests were performed to compare the difference in fit between the bi-factor model and a singlefactor model, as well as the originally hypothesised correlated four-factor model measuring trustworthiness, self-mastery, empowerment and accountability. The chi-square difference test was considered justified because the one-factor and fourfactor models are parametrically nested in the bi-factor model. ${ }^{2}$

1.The statistical significance of the factor loadings were tested by testing $H: \lambda=0$; $i=3,4,5, \ldots, 118 ; j=1,2,3, \ldots, 58 ; k=1,2,3,4$ against $H_{a i}: I_{j k}=0 ; i=3,4,5, \ldots, 118$; $i=3,4,5, \ldots, 118 ; j=1,2,3, \ldots$,
$j=1,2,3, \ldots, 58 ; k=1,2,3,4$.

2.Model $A$ is considered nested in model $B$ if the two models contain the same indicator variables and model A can be derived from model B by constraining specific parameters in model B to zero or to one (Vandenberg \& Grelle 2009). 
TABLE 5: The PHI matrix of the intercorrelations between the group factors.

\begin{tabular}{lccccc}
\hline Variable & Trust & Selfm & Empower & Account & Gen \\
\hline Trust & 1.000 & - & - & - & - \\
Selfm & 0.441 & 1.000 & - & - & - \\
Empower & -0.141 & -0.290 & 1.000 & - & - \\
Account & 0.566 & 0.032 & 0.403 & 1.000 & - \\
Gen & - & - & - & - & 1.000 \\
\hline
\end{tabular}

Trust, trustworthiness; Selfm, self-mastery; Empower, empowerment; Account, accountability; Gen, general factor.

An adjusted chi-square difference test (Satorra \& Bentler, 2010) indicated that the bi-factor model achieved a significantly $(p<0.01)$ better fit with the data than both the correlated four-factor model and the one-factor model (see Table 3).

\section{Discussion}

The bi-factor analysis disclosed that the PLS measures a strong general principled leadership factor and four relatively weak residualised group factors, which link with the trustworthiness, self-mastery, empowerment and accountability dimensions. Although the results support a qualitative distinction between a general principled leadership factor and the four group factors, the low factor loadings indicate that the group factors do not yield precise enough measures of unique aspects of principled leadership to be useful in practical applications (De Bruin \& Du Plessis, 2015).

The purpose of the study was to develop a new scale, the PLS, an integrated, value-based leader behaviour scale measuring leader behaviour in middle to top management. From a bi-factor perspective, the calculation of a total score for the PLS can be justified because a strong general factor (principled leadership) was revealed and each item adequately and significantly loaded on the general factor (De Bruin \& Du Plessis, 2015). The statistical results of the bifactor CFA rendered the overall PLS a potentially constructvalid scale, which may sufficiently measure the collective behaviours inherent in transformational, servant, authentic and ethical leadership.

\section{Practical managerial implications and recommendations}

The literature provides ample proof that the disease of unethical behaviour in organisations cannot be healed through external measures alone. Organisational leaders who are serious about wanting to eradicate unethical behaviour in their organisations should therefore cease efforts that solely utilise an 'outside-in' approach to develop ethical behaviour in their employees. They should instead start by taking an honest look at their own behaviour to determine whether it is principled enough to emulate. If not, they should address the unethical issues in their own conscience and behaviour first.

Following this, it is critical that organisational leaders evaluate whom they select into and keep in leadership positions, as the cascading effect (Mayer et al., 2009) of leader behaviour will determine the type of behaviour and values that will filter down through the organisation. For this, a selection and personal development process, which makes use of methods from which valid inferences can be drawn about the inherent principled behaviour of a potential leader, is necessary.

This study has found preliminary evidence that the PLS is a construct-valid measure of principled leader behaviour, which could be utilised to assess applicants and incumbents to determine the extent to which their behaviour is principled. The PLS will aid selection by providing insight into the principled behaviour of applicants. By utilising the PLS to assess incumbents, the PLS could pinpoint development areas in the leader's principled behaviour around which coaching and personal development plans can be tailored.

Based on the literature studied, the principled behaviour of leaders should not only encourage principled behaviour in followers through the cascading effect, but also influence several organisational outcomes positively. As principled leadership is aggregated from the four value-based leadership theories, it follows that the organisational outcomes of valuebased leadership could also be expected from a principled leader. Organisations that employ and develop principled leaders should therefore expect greater trust between leaders and followers, which leads to positive employee behaviours such as organisational citizenship behaviour $(\mathrm{OCB})$, organisational commitment, employee engagement, team effectiveness and leader effectiveness (Den Hartog, Shippers, \& Koopman, 2002; Engelbrecht \& Chamberlain, 2005; Engelbrecht et al., 2017; Engelbrecht, Wolmarans, \& Mahembe, 2017; Hassan \& Ahmed, 2011; Mahembe \& Engelbrecht, 2014; Newman, Kiazad, Miao, \& Cooper, 2014; Van Dierendonck \& Nuitjen, 2011).

\section{Conclusion of managerial implications}

Organisations that invest in assessing the principled leader behaviour of their top management, and in recruiting and developing principled leaders, should be confident that they have the best calibre role models in place to ensure the cascading of principled behaviour down the ranks of the organisations. Over time, such organisations should be able to restore the behaviour of their workforce towards ethical, principled behaviour, which, in turn, will result in greater trust and cooperation between members of the organisation, as well as enhanced organisational effectiveness.

\section{Limitations of the study and suggestions for future research}

This study was successful in developing the PLS, in that it yielded initial evidence of construct validity. However, the study encountered certain limitations and revealed areas for future research, which should be considered.

The demographics of the sample used in the study should ideally have been representative of the racial demographics of South Africa. Unfortunately, the sample did not live up to this requirement. This is often a problem when purposive non-probability sampling is used. Choosing a sample that shows better representation of the racial demographics in a 
future study would be highly recommended, especially to enhance its worthiness as a South African scale.

A study in which the PLS is assessed within a structural model, together with a scale from one or more of the four value-based leadership theories would serve to establish its discriminant and convergent validity in comparison to such scales. This would aid in further proving its claim to be an integrated value-based leadership scale.

The results indicated that no sufficient evidence could be found that the PLS validly measured the four postulated dimensions of principled leadership. Based on the results of the study, a bi-factor model was tested and a good model fit was found. However, the bi-factor model should be tested on a new sample to corroborate the construct validity of the PLS.

The PLS might be improved by writing additional items and by rewriting some of the existing items to reflect the theoretical dimensions more accurately. This would allow for a detailed multidimensional examination of principled leadership behaviour. Valid dimensions would create a logical grouping of principled leader behaviours around which personal development plans can be created.

It would be valuable to expand the PLS to a self-rating scale. The PLS could then be used as a full-fledged $360^{\circ}$ assessment tool. This would lead to improved insights and better identification of development areas that can be achieved with the other-rating scale alone.

The researchers suggest that a longitudinal study that tests principled leadership over time would be valuable. Measuring the degree of principled behaviour over time, while instituting interventions to develop principled behaviour in leaders, would be invaluable in establishing the true, practical worth of the PLS.

Finally, it is suggested that future research should develop a structural model to further evaluate the construct validity of the PLS by including latent variables such as moral intelligence, trust, organisational justice, ethical culture, OCB and leader effectiveness. A potentially fruitful area of future research is to examine whether in structural equation models the group factors are able to predict these correlates and outcomes of principled leadership after controlling for the general factor.

\section{Conclusion}

This study examined the factor structure of the PLS using bi-factor analysis to evaluate a general principled leadership factor and four group factors that link with trustworthiness, self-mastery, empowerment and accountability. In conclusion, the results provide some support for the construct validity of the PLS. As expected, a general factor dominated the responses to the items and it appears that researchers may safely compute a total score to represent respondents' principled leadership.
The study proved valuable in that it sought to identify leader behaviour which, when cascaded down the ranks of an organisation, may help to curb the pandemic of corruption plaguing South Africa. Furthermore, the study made a first attempt to integrate the inherent behaviours of four valuebased leadership theories into one construct, principled leadership, and to develop a potentially valid new leadership assessment tool, the PLS, to measure this construct. While further research to validate the findings of this study is suggested, the PLS in its current form provides a tool by which the overall principled behaviour of a leader can be assessed sufficiently. This tool can provide organisations with valuable information about leadership abilities of applicants during the selection process. Furthermore, the PLS could be used to identify development areas for incumbents of leadership positions, or to develop those earmarked for leadership positions at a future point in their careers.

\section{Acknowledgements}

The authors would like to thank Prof. Callie Theron for his insightful communication and valuable suggestions.

\section{Competing interests}

The authors declare that they have no financial or personal relationships that may have inappropriately influenced them in writing this article.

\section{Authors' contributions}

Both K.H. and A.S.E. were responsible for the conceptualisation of the study, the interpretation of the results and writing of the article. K.H. was also responsible for the data collection and statistical analyses.

\section{References}

Allio, R. J. (2005). Leadership development: Teaching versus learning. Management Decision, 43, 1071-1077. https://doi.org/10.1108/00251740510610071

Barbuto, J. E., \& Wheeler, D. W. (2006). Scale development and construct clarification of servant leadership. Group and Organisation Management, 31(3), 300-326. https://doi.org/10.1177/1059601106287091

Brown, M. E., Trevino, K., \& Harrison, D. A. (2005). Ethical leadership: A social learning perspective for construct development and testing. Organisational Behaviour and Human Decision Processes, 97, 117-134. https://doi.org/10.1016/j.obhdp. 2005.03.002

Chen, F. F., West, S. G. \& Sousa, K. H. (2006). A comparison of bifactor and secondorder models of quality of life. Multivariate Behavioral Research, 41(2), 189-225. https://doi.org/10.1207/s15327906mbr4102_5

Cianci, A. M., Hannah, S. T., Roberts, R. P., \& Tsakumis, G. T. (2014). The effects of authentic leadership on followers' ethical decision-making in the face of temptation: An experimental study. The Leadership Quarterly, 25, 581-594. temptation: An experimental study. The Leade
https://doi.org/10.1016/j.leaqua.2013.12.001

Coetzer, M. F., Bussin, M. H. R., \& Geldenhuys, M. (2017). Servant leadership and work-related well-being in a construction company. SA Journal of Industrial Psychology, 43, 1-10. https://doi.org/10.4102/sajip.v43i0.1478

De Bruin, G. P, \& Du Plessis, G. A. (2015). Bifactor analysis of the Mental Health Continuum-Short Form (MHC-SF). Psychological Reports, 116(2), 438-446. https://doi.org/10.2466/03.02.PR0.116k20w6

Den Hartog, D. N., Shippers, M. C., \& Koopman, P. L. (2002). The impact of leader behaviour on trust in management and co-workers. SA Journal of Industrial Psychology, 28(4), 29-34. https://doi.org/10.4102/sajip.v28i4.75

Engelbrecht, A. S., \& Chamberlain, L. (2005). The influence of transformational leadership on organisational citizenship behaviour through justice and trust. Management Dynamics, 14(1), 2-12.

Engelbrecht, A. S., Heine, G., \& Mahembe, B. (2017). Integrity, ethical leadership, trust and work engagement. Leadership and Organisation Development Journal, 38(3), 368-379. https://doi.org/10.1108/LODJ-11-2015-0237 
Engelbrecht, A. S., Van Aswegen, A. S., \& Theron, C. C. (2005). The effect of ethical values on transformational leadership and ethical climate in organisations. South African Journal of Business Management, 36(2), 19-26.

Engelbrecht, A. S., Wolmarams, J., \& Mahembe, B. (2017). Effect of ethical leadership and climate on effectiveness. SA Journal of Human Resource Management, 15, 1-10. https://doi.org/10.4102/sajhrm.v15i0.781

Eisenbeiss, S. A. (2012). Re-thinking ethical leadership: An interdisciplinary integrative approach. The Leadership Quarterly, 23, 791-880. https://doi.org/10.1016/j. leaqua.2012.03.001

Giessner, S., \& Van Quaquebeke, N. (2010). Using a relational models perspective to understand normatively appropriate conduct in ethical leadership. Journal of Business Ethics, 95, 43-55.

Hassan, A., \& Ahmed, F. (2011). Authentic leadership, trust and work engagement. International Journal of Human and Social Sciences, 6(3), 164-170.

Hemsworth, D., Muterera, J., \& Baregheh, A. (2013). Examining Bass's transformational leadership in public sector executives: A psychometric properties review. The Journal of Applied Business Research, 29(3), 853-862. https://doi.org/10.19030/ Journal of Applied

Hinkin, T. R. (1998). A brief tutorial on the development of measures for use in survey questionnaires. Organisational Research Methods, 1(1), 104-121. https://doi. org/10.1177/109442819800100106

Hooper, D., Coughlan, J., \& Mullen, M. (2008). Structural equation modelling: Guidelines for determining model fit. Journal of Business Research Methods, 6(1), 53-60.

Hsu, C., \& Sandford, B. A. (2007). The Delphi technique: Making sense of consensus. Practical Assessment, Research and Evaluation, 12(10), 1-7.

Institute of Directors in Southern Africa (IoDSA). (2016). The King report on corporate governance for South Africa. Retrieved from http://www.iodsa.co.za

Jöreskog, K. G., \& Sörbom, D. (2006). LISREL8: User's reference guide. Chicago, IL: Scientific Software International, Inc.

Kalshoven, K., Den Hartog, D. N., \& De Hoogh, A. H. (2011). Ethical Leadership at Work questionnaire (ELW): Development and validation of a multidimensional measure. The Leadership Quarterly, 22, 51-69. https://doi.org/10.1016/j.leaqua. 2010.12.007

Kinnear, R. T., Kernes, J. L., \& Dautheribes, T. M. (2000). A short list of universal mora values. Counselling and Values, 45, 4-16. https://doi.org/10.1002/j.2161-007X.2000. tb00178.x

Mahembe, B., \& Engelbrecht, A. S. (2014). The relationship between servant leadership, organisational citizenship behaviour and team effectiveness. SA Journal of Industria Psychology, 40(1), 1-10. https://doi.org/10.4102/sajip.v40i1.1107

Mayer, D. M., Kuenzi, M., Greenbaum, R., Bardes, M., \& Salvador, R. (2009). How low does ethical leadership flow? Test of a trickle-down model. Organisationa Behaviour and Human Decision Processes, 108, 1-13. https://doi.org/10.1016/j. obhdp.2008.04.002

McKenzie, S. B., Podsakoff, P. M., \& Podsakoff, N. P. (2011). Construct measurement and validation procedures in MIS and behavioural research: Integrating new and existing techniques. MIS Quarterly, 35(2), 293-334. https://doi.org/10.2307/23044045
Neider, L. L., \& Schriesheim, C. A. (2011). The Authentic Leadership Inventory (ALI): Development and empirical tests. The Leadership Quarterly, 22, 1146-1164. https://doi.org/10.1016/j.leaqua.2011.09.008

Newman, A., Kiazad, K., Miao, Q., \& Cooper, B. (2014). Examining the cognitive and affective trust-based mechanisms underlying the relationship between ethical leadership and organisational citizenship: A case of the head leading the heart. Journal of Business Ethics, 123, 113-123. https://doi.org/10.1007/s10551-0131803-2

Nunnally, J. C. (1978). Psychometric theory (2nd edn.). New York: McGraw-Hill.

Pallant, J. (2013). SPSS survival guide: A step by step guide to data analysis using IBM SPSS (5th edn.). Berkshire: McGraw-Hill.

Pillay, P. (2014). Integrity leadership. African Journal of Public Affairs, 7(2), 27-35.

Reise, S. P. (2012). The rediscovery of bifactor measurement models. Multivariate Behavior Research, 47(5), 667-696. https://doi.org/10.1080/00273171.2012. 715555

Sauser, I. W. (2005). Ethics in business: Answering the call. Journal of Business Ethics, 58, 345-357. https://doi.org/10.1007/s10551-004-5715-z

Satorra, A., \& Bentler, P. M. (2010). Ensuring positiveness of the scaled difference chi-square test. Psychometrika, 75(2), 243-248. https://doi.org/10.1007/s11336009-9135-y

Schwartz, M. S. (2005). Universal moral values for corporate codes of ethics. Journal of Business Ethics, 59, 27-44. https://doi.org/10.1007/s10551-005-3403-2

Sendjaya, S., Sarros, J. C., \& Santora, J. C. (2008). Defining and measuring servant leadership behaviour in organizations. Journal of Management Studies, 45(2), 402-424. https://doi.org/10.1111/j.1467-6486.2007.00761.x

Spangenberg, H., \& Theron, C. C. (2005). Promoting ethical follower behaviour through leadership of ethics: The development of the Ethical Leadership Inventory (ELI). South African Journal of Business Management, 36(2), 1-18.

Vandenberg, R. J., \& Grelle, D. M. (2009). Alternative model specifications in structural equation modelling: Facts, fiction and truth. In C. E. Lance \& R. J. Vandenberg (Eds.), Statistical and methodological myths and urban legends: Doctrine, verity and fable in organizational and social sciences (pp. 165-191). New York: Taylor and Francis.

Van Dierendonck, D., \& Nuitjen, I. (2011). The servant leadership survey: Development and validation of a multidimensional measure. Journal of Business Psychology, 26 249-267. https://doi.org/10.1007/s10869-010-9194-1

Walumbwa, F. O., Avolio, B., Gardner, W. L., Wernsing, T. S., \& Peterson, S. J. (2008). Authentic leadership: Development and validation of a theory-based measure, Journal of Management, 34(1), 89-126. https://doi.org/10.1177/014920630 7308913

Yukl, G. (1999). An evaluative essay on current conceptions of effective leadership. European Journal of Work and Organizational Psychology, 8(1), 33-48. https:// doi.org/10.1080/135943299398429

Yukl, G., Mahsud, R., Hassan, S., \& Prussia, G. E. (2013). An improved measure of ethical leadership. Journal of Leadership and Organisational Studies, 20(1) 38-48. https://doi.org/10.1177/1548051811429352 